\title{
Dimensões do sofrimento psíquico em estudantes universitários estrangeiros
}

\author{
Júlia de Freitas Girardi \\ Université de Toulouse - Jean Jaurès, Toulouse, França \\ Lucienne Martins Borges \\ Universidade Federal de Santa Catarina, SC, Brasil
}

\begin{abstract}
Resumo
Os estudantes universitários estrangeiros fazem parte da categoria de imigrantes voluntários, que se desloca para realizar a formação superior em outro país. O processo imigratório acarreta uma série de desafios e não deixa de ter consequências no psiquismo dos sujeitos. Dessa forma, objetivou-se apresentar e discutir características do sofrimento psíquico desses estudantes estrangeiros residentes em Florianópolis. Para tanto, produziu-se uma pesquisa qualitativa na qual os dados foram coletados a partir de entrevistas semiestruturadas com 15 participantes. Os dados foram analisados por meio da técnica de análise de conteúdo, com suporte do software Atlas.ti. Assim, foi possível distinguir três subcategorias de análise: sintomas físicos, sociais e psicológicos. Observou-se um alto índice de somatizações, experiências de discriminação e relatos de sentimento de não pertencimento. Em conclusão, ressalta-se a necessidade de se refletir sobre formas de amenizar o sofrimento e de pensar em programas específicos para essa população, principalmente no contexto universitário.
\end{abstract}

Palavras-chave: Imigração; Saúde mental; Sofrimento psíquico; Estudantes universitários estrangeiros; Estudantes internacionais.

\section{The dimentions of psychological suffering in foreign university students}

\begin{abstract}
Foreign university students are a part of the category of voluntary immigrants, who travel with the objective of completing higher education in another country. The immigration process entails a series of challenges and has consequences in the psyche of these individuals. Thus, the objective here is to present and discuss characteristics of the psychological suffering of these foreign students living in Florianópolis. For that, a qualitative research was conducted; the data were collected through semi-structured interviews with 15 participants. For data analysis we used the technique of content analysis, supported by the Atlas.ti software. It was distinguished three subcategories of analysis: physical, social and psychological symptoms. It was observed a high index of somatizations, experiences of discrimination and reports of feelings of non-belonging. In conclusion, it is necessary to reflect on ways to soften the suffering and to thinking about specific programs for this population, especially in the university context.
\end{abstract}

Keywords: Immigration; Mental health; Psychological suffering; Foreign university students; International students.

\section{Dimensiones del sufrimiento psíquico de estudiantes universitarios extranjeros}

\section{Resumen}

Los estudiantes universitarios extranjeros forman parte de la categoría de inmigrantes voluntarios que se desplaza para realizar su educación superior en otro país. El proceso inmigratorio conlleva a una serie de desafíos, así como a consecuencias en el psiquismo de estos individuos. el objetivo de este trabajo constituye en presentar y discutir las características del sufrimiento psíquico de los estudiantes extranjeros que residen en Florianópolis. Para ello, se ha realizado una investigación cualitativa, en la cual, han sido recolectados datos a través de entrevistas semi-estructuradas con 15 participantes. Los datos han sido analizados por medio de la técnica de análisis de contenido, con soporte del software Atlas.ti. Así, ha sido posible distinguir tres subcategorías de análisis: síntomas físicos, sociales y psicológicos. Se ha observado un alto índice de somatizaciones, experiencias de discriminación y relatos de sentimientos de no pertenecer. En conclusión, se resalta la necesidad de reflexionar acerca de formas de disminuir el sufrimiento y de considerar programas específicos para esta población, principalmente en el contexto universitario.

Palabras clave: Inmigración; Salud mental; Sufrimiento psíquico; Estudiantes universitarios extranjeros; Estudiantes internacionales. 


\section{Introdução}

Estudantes universitários estrangeiros, ou estudantes internacionais, são indivíduos que se deslocam do seu país de origem para outro com o objetivo de efetivar uma formação superior completa - o que os diferencia dos intercambistas -, caracterizandose como uma imigração voluntária. Em 2010, essa categoria de imigração abrangia mais de 4.1 milhões de pessoas no mundo, apontando um crescimento de $7,1 \%$ ao ano (OECD, 2012). São diversos os motivos que levam esses sujeitos a escolherem frequentar um curso superior em outro país: o valor atribuído pela população de origem a uma formação internacional, o aprendizado de uma nova cultura e novo idioma, a crença em maiores possibilidades de conseguir emprego ao retornarem (Andrade \& Teixeira, 2009; Liu \& Winder, 2014). Cada país possui um perfil diferente de universitários estrangeiros e deve levar em consideração as políticas internacionais de cada um, suas fronteiras geográficas bem como as dimensões culturais e o idioma (OECD, 2012).

No Brasil, como no mundo, também se tem observado a tendência de receber essa categoria de imigrantes, principalmente após o governo Lula - de 2003 a 2010 -, em decorrência do impulso nos acordos bilaterais na área da educação superior, nomeadamente com os Países Africanos de Língua Oficial Portuguesa - PALOP (Gusmão, 2011). Entre os acordos internacionais do Brasil, no âmbito do ensino superior, destacam-se o Programa de Estudantes-Convênio de Gradução - PEC-G - e o Programa de Estudantes-Convênio de Pós-Graduação - PEC-PG -, o primeiro vigente desde 1965 e o segundo, desde 1981. Ambos os programas contam com a participação de 56 países, sendo que $78 \%$ dos universitários estrangeiros do PEC-G são provenientes do PALOP e $75 \%$ dos estudantes do PEC-PG são de origem latino-americana (Divisão de Temas Educacionais, n.d.). Após o terremoto de 2010, no Haiti, surge o Pró-Haiti, convênio que possibilita aos estudantes haitianos terminarem seus cursos superiores no Brasil (CAPES, 2010). Além desses programas, também existem aqueles estudantes que chegam ao Brasil por conta própria ou por acordos de universidades brasileiras com o governo de países específicos (Fonseca, 2009).

A imigração é um fenômeno complexo, com impactos socioculturais, intrapsíquicos e outros. Esse processo implica na necessidade de recomeçar e ressignificar diversas esferas da vida cotidiana que vão desde clima, alimentação, idioma, relações, normas e valores culturais, até dimensões da própria subjetividade e identidade desses sujeitos que deixam seu país de origem para dar continuidade à sua vida em um outro país, até então desconhecido (Andrade \& Teixeira, 2009; Jibrin, Boeira-Lodetti, \& MartinsBorges, 2017; Silva \& Morais, 2012). Além disso, no caso dos estudantes universitários estrangeiros, eles também precisam se adaptar tanto ao novo contexto acadêmico como ao processo de ensino-aprendizagem, que são diferentes daqueles de seus países de origem (Andrade \& Teixeira, 2009; Chalungsooth \& Schneller, 2011).

O imigrante encontra-se afastado do seu referencial cultural de origem, no qual se constituiu como sujeito e a partir do qual significava sua realidade interna e externa. Entre outros fatores, a perda desse quadro de referência pode colocar o sujeito em uma posição de vulnerabilidade (Martins-Borges, 2013). Nesse contexto é comum o aparecimento de questionamentos identitários que requerem que a nova realidade seja ressignificada, o que pode provocar impactos psicológicos, vulnerabilidade, sofrimento psíquico, como o isolamento, queixas somáticas, ansiedade, depressão (Martins-Borges, 2013; Pirlot, 2011). Coutinho, Rodrigues e Ramos (2012) também destacam queixas relacionadas à insônia, irritabilidade, dificuldade de concentração e fadiga. No entanto, as vicissitudes desencadeadas pela imigração dependem de uma série de fatores como a situação socioeconômica do sujeito no país de acolhimento, as redes sociais e de apoio, as políticas migratórias do país de acolhimento e as características pessoais dos sujeitos (MartinsBorges, 2013).

Devido à abrangência dos estudantes universitários estrangeiros no mundo, são diversos os estudos internacionais com essa população, no entanto, eles costumam focar na adaptação social, no desenvolvimento acadêmico e na saúde mental (Yakushko, Davidson \& Sanford-Martens, 2008). Já, no contexto nacional, existe carência de estudos que investiguem os impactos psicológicos e as necessidades específicas dessa população (Andrade \& Teixeira, 2009; Girardi, 2015). Ao se considerar esses apontamentos, o presente artigo possui como objetivo compreender as diferentes dimensões de sofrimento psíquico encontradas em estudantes universitários estrangeiros residentes na cidade de Florianópolis, no Brasil.

\section{Método}

De forma a contemplar o objetivo proposto, a pesquisa realizada seguiu um enquadramento qualitativo, descritivo e exploratório. Assim, participaram dessa pesquisa quinze estudantes universitários estrangeiros. Esses foram selecionados de acordo 
com os seguintes critérios: a) serem imigrantes com visto temporário ou permanente, b) residirem no Brasil há pelo menos um ano, c) estarem devidamente matriculados na Universidade Federal de Santa Catarina - UFSC -, e d) falarem português. Em relação aos 15 participantes que compuseram a amostra dessa pesquisa, sete estavam cursando graduação e oito pósgraduação, sendo dez homens e cinco mulheres. Os participantes são originários de 8 países diferentes (Haiti, Colômbia, Cuba, Cabo Verde, Guiné-Bissau, Panamá e Moçambique) e o tempo de residência no Brasil variou entre 1 ano e 6 meses e 8 anos, com uma média de 3 anos e 9 meses.

Os dados foram coletados por meio de entrevistas semiestruturadas, realizadas no período de julho a setembro de 2015. A escolha do local para a realização das entrevistas foi proposta a cada um dos participantes, de modo a permitir a escolha de um espaço em que se sentissem à vontade. Todos os participantes deram preferência a lugares da própria universidade: seus respectivos laboratórios de pesquisa ou, quando não tinham preferência, lhes era proposto a sala do Núcleo de Estudos sobre Psicologia, Migrações e Culturas (NEMPsiC), laboratório ao qual essa pesquisa está vinculada. $\mathrm{O}$ acesso a esses participantes foi possível mediante a utilização da técnica Bolade-neve (snowball), que consiste em indicações dos próprios participantes de pessoas que compõem suas redes sociais e que se enquadravam nos critérios estabelecidos. O áudio das entrevistas realizadas foi gravado e posteriormente transcrito na íntegra.

A análise desses dados apoiou-se na técnica de análise de conteúdo proposta por Bardin (2002) com auxílio do Atlas.Ti, software especializado no suporte de desenvolvimentos conceptuais a partir de tratamento e codificação de material qualitativo (Flick, 2014). É importante ressaltar que esta pesquisa foi avaliada e aprovada pelo Comitê de Ética e Pesquisa com Seres Humanos da Universidade Federal de Santa Catarina (CEPSH/UFSC).

Dessa forma, por meio da técnica de análise de conteúdo das entrevistas foi possível caracterizar a categoria de sofrimento psíquico em três subcategorias temáticas: sintomas físicos, manifestações sociais e sintomas psicológicos. Desse modo, segue-se aqui a discussão de cada umas dessas subcategorias.

\section{Sintomas Físicos}

“Enxaqueca... muita. Muita. Não sabia o que era isso, até que... eu tinha dor de cabeça [no país de origem], mas normal, que só tomar um remédio, um paracetamol e passa, mas do jeito daqui, de eu ter vontade de vomitar, de eu não suportar a luz, foi novo pra mim. Lá era mais acho que físico, por estar muito tempo no sol trabalhando, coisas assim, mas aqui foi mais pelo estresse." (P5 - Colômbia)

"Insônia. Muita insônia. Inclusive atualmente eu luto para tentar dormir cedo e acordar cedo. Luta. Este é um dilema meu." (P13 - Moçambique)

"Estava muito cansado assim, no primeiro semestre também, tava muito cansado mesmo, cheguei a ter que descansar na aula, muito cansado, muito." (P3 - Cabo Verde)

Esses trechos das falas dos participantes trazem a dimensão física do sofrimento psíquico, isto é, aquela que se apresenta no corpo. Todos os quinze participantes dessa pesquisa trouxeram pelo menos um exemplo de sintoma físico constante em seu cotidiano, sendo os principais: dores de cabeça, problemas no estômago, cansaço, alterações no sono, entre outros. É interessante pensar que manifestações físicas relacionadas ao estresse são comumente relatadas em estudantes universitários em geral, principalmente em momentos de maiores tensões como ao realizar provas e escreverem suas dissertações. No entanto, duas características observadas nos discursos dos participantes chamam a atenção e parecem sugerir um acréscimo de complexidade a essas manifestações, uma vez que são permeadas pelos conflitos advindos da imigração. Primeiro, os sintomas aparecem somente após a imigração, ou seja, não ocorriam no país de origem, ou, quando já estavam presentes, eram menos intensas e não frequentes. $\mathrm{O}$ segundo aspecto refere-se à relação entre as manifestações com momentos de estresse, de tristeza ou de dificuldades, conforme pode ser observado nos exemplos a seguir:

"É dores de cabeça era por estresse mesmo, estresse de estudar demais, de ler demais, de tentando entender coisas dificil demais, de dormir tarde, de ter medo de não conseguir... essas coisas." (P2 - Haiti)

"Então foi um pouco assim, eu sei que eu já percebi que, cada vez que eu fico muito estressada, seja pelo trabalho, por qualquer outra coisa, eu já fico doente e [...], outra vez tive um ataque de gastrite, que foi quando eu estava escrevendo o projeto, dai eu nem queria sair de casa para eu poder conseguir me concentrar mais, porque não estava fazendo do jeito certo, achava que se eu ficava lá e eu não saía e só escrevia e escrevia eu ia conseguir terminar mais rápido, mas não foi assim." (P5 - Colômbia) 
"Fiquei doente, eu fiquei doente porque nunca dormi ficando me preparando, preparando, preparando, ai eu fiquei com anemia essas coisas [...], dai eu fui pro hospital, pra emergência, dai quando eu cheguei me atendeu me deu soro essas coisas, dai eles ficaram tomando sangue tomando sangue nunca deu nenhum resultado até agora [...], só fiquei anêmico e todo o meu corpo tava doente, uma fadiga, como se fosse um estado crônico de fadiga entendeu?" (P9 - Haiti)

Essas duas características muito particulares levam a pensar que esses sintomas vão para além da manifestação física, isto é, são uma forma de expressão simbólica de conflitivas psíquicas; nesse sentido, podese falar em quadros de somatizações (Pirlot, 2011). As queixas somáticas são extremamente comuns em imigrantes (Coutinho, Rodrigues, \& Ramos, 2012; Khawaja \& Dempsey, 2007; Martins-Borges, 2013; Pirlot, 2011). Uma das hipóteses sobre a somatização como forma privilegiada de expressão de sofrimento nesses sujeitos é a busca inconsciente por uma simbolização em comum entre o universo cultural de origem e o de acolhimento. Nesse sentido, pode-se dizer que a linguagem encontra-se inibida, uma vez que esta ultrapassa não apenas a língua, mas a toda a gama de significados e símbolos que foram desenvolvidos dentro de uma cultura que se encontra em falta. Dessa forma, o corpo torna-se linguagem de modo a dizer que algo não está bem.

\section{Manifestações Sociais}

Nessa subcategoria compreendem-se por manifestação social as formas de sofrimento que surgem em decorrência do olhar e do contato com o outro, sendo esse outro, em geral, membro do país de acolhimento. Assim, fala-se aqui da leitura e significação realizada pelos participantes de experiências do contato com o outro e com a diferença cultural. Primeiramente, destaca-se a vivência de perceber-se estrangeiro pelo olhar do outro, conforme os seguintes exemplos:

"Tenho conhecido pessoas que não gostam e que acham que a gente tá... tirando alguma coisa de vocês, sabe? Que 'ah, veio um estrangeiro ficar com uma bolsa da gente. Uma bolsa de um brasileiro'. Você escuta esse tipo de comentário. Especialmente... assim de pessoas, de professores também." (P14 - Colômbia)

"Acho que tem algumas... tem algumas situações é... eles tem um certo 'ah porque você ganha bolsa, está aqui com o dinheiro do povo, dinheiro do imposto, nosso' tudo isso." (P8 - Cuba)
A forma como os estudantes universitários estrangeiros são recebidos pela sociedade de acolhimento varia de acordo com características dos diferentes países. Assim, enquanto alguns países são mais abertos e os vêm como necessários para a economia local, outros já são mais fechados e os percebem como sujeitos que estão retirando oportunidades de estudantes locais (Liu \& Winder, 2014).

Outro tipo de manifestação social trazido pelos participantes refere-se à discriminação racial. Aqui é importante ressaltar que a discriminação racial foi apontada pelos participantes originários de países da África e do Haiti, não sendo notada pelos participantes de países da América Latina.

"E ai fui perguntar pras pessoas elas não paravam, meio que ignoravam, olhavam estranho assim, 'pô tem alguma coisa errada' a pessoa fica mal assim na hora, isso não é normal no meu país nem imaginava que fosse, [...] Tu não entendes o que isso é, tua reação... tu se sente mal por causa disso. Na rua também as pessoas... várias pessoas assim... estava andando na calçada as pessoas desviam assim, tinha medo talvez não sei é preconceito talvez porque tu parece que mora no morro." (P3 - Cabo Verde)

“Dai, por exemplo, se tu tirar a pele, debaixo da pele somos iguais, entendeu? Ai vai depender de cada pessoa. E é como já tinha falado: as pessoas daqui são um pouco fechadas. Daí, eu sou, tipo, um pouco observador. Quando eu percebo que já existe tal coisa, dai eu não me, tipo eu tento o máximo possivel não me inserir pra não sentir o efeito. [...] vários dos meus amigos falaram isso, sempre que eles sofreram preconceitos, na universidade, com professores, com os próprios estudantes. Principalmente na hora de fazer trabalho em equipe. Por isso que eu prefiro fazer trabalho sozinho. " (P15 - Haiti)

São diversos os estudos que trazem a dimensão da discriminação em relação aos estudantes universitários estrangeiros (Constantine et al., 2005; Fonseca, 2009; Khawaja \& Dempsey, 2007; Liu \& Winder, 2014; Silva \& Morais, 2012). Grande parte desses estudantes não possuem experiências anteriores de imigração, ou seja, é a primeira vez que saem de seus países de origem para viver em outro. Da mesma forma, muitas vezes relatam que não tiveram experiências discriminatórias em seus países de origem, uma vez que é somente após a imigração que passam a fazer parte de uma minoria (Constantine et al., 2005). 
Especificamente em relação a estudos com estudantes universitários estrangeiros, no Brasil, a discriminação racial também ocupa lugar de destaque nas pesquisas, principalmente com estudantes originários de países da África Subsaariana (Fonseca, 2009; Silva \& Morais, 2012). Nesse contexto, sublinha-se a falta de conhecimento dos brasileiros sobre as diferentes culturas africanas, exemplificadas pelo estereótipo de africanos como selvagens ou na compreensão da África como um continente dominado por guerras civis (Fonseca, 2009).

Aqui é necessário apontar o papel que a discriminação racial pode ter como potencializador de comportamentos de isolamento e perda de autoestima (Khawaja \& Dempsey, 2007). Nesse sentido pode-se observar, nos exemplos dos participantes dessa pesquisa, mal-estar e comportamentos de evitação em relação a situações, nas quais a discriminação possa acontecer. Isso pode estar relacionado ao fato de os participantes relatarem uma dificuldade de se relacionarem com brasileiros, restringindo o contato somente para questões acadêmicas e privilegiando as relações sociais com conterrâneos e outros estrangeiros, o que também foi observado em outros estudos com essa população (Constantine et al., 2005; Liu \& Winder, 2014; Silva \& Morais, 2012).

Por fim, também observaram-se diversos relatos dos participantes de experiências de desqualificação de suas origens por pessoas do país de acolhimento, conforme os seguintes trechos:

“Tinham algumas pessoas que tá, o conceito que eles têm na Colômbia, que eles assistem no jornal, das FARC, guerrilha, cocaína, isso e aquilo, era no começo tinha muitas coisas que falavam, quando eu conversava com eles e falava, "ah, não tem só isso, tem café, tem flores”. [...] Então era muita coisas assim que as pessoas não conheciam." (P5 - Colômbia).

“A violência ou as drogas, sabe. É como um rótulo assim que a gente tem. [...] Então isso é assim um preconceito, assim de... olhares estranhos [...], na verdade no começo meio que me deixava meio sem graça, sabe assim. Então... Mas... Mas eu acho que depois que eles... depois quando eu conheci mais gente, sabe, ficou mais tranquilo, já sabem que a gente vem aqui, não para tirar nada, só para ter uma oportunidade." (P14 - Colômbia)

Essas falas refletem a desvalorização, pelo outro, de suas origens culturais, isto é, de sua identidade, uma vez que a relação sujeito-cultura é indissociável. Os exemplos trazidos nessa categoria assinalam o contato com a diferença cultural como a condição que evidencia um conflito de valores e o confronto do sujeito com sua identidade cultural. Toda essa conflitiva pode gerar vulnerabilidade, sentimentos de inferioridade, confusão identitária, isolamento (Andrade \& Teixeira, 2009; Khawaja \& Dempsey, 2007; Yakushko, Davidson, \& Sanford-Martens, 2008). Também são essas manifestações sociais que conferem a esses sujeitos a posição de estrangeiros, de serem "de fora" e, portanto, a condição de não pertencimento e de não possuir um lugar na sociedade de acolhimento.

\section{Sintomas Psicológicos}

Todos os imigrantes e, por conseguinte, também os estudantes universitários estrangeiros são sujeitos que se encontram em uma situação "entre dois", isto é, entre dois países e dois universos culturais diferentes. Nesse contexto, surge o duplo desejo: o de manter o referencial cultural de origem (que tende a estar relacionado com a identidade do sujeito), mas, ao mesmo tempo, também fazer uma ponte com o país de acolhimento, que é a realidade exterior atual na qual o sujeito está inserido. Esse conflito interior colocaos em posição de questionar sua identidade e buscar novas formas de ser, o que por si só já acarreta um nível de estresse que pode gerar uma série de sintomas psicológicos (Martins-Borges, 2013).

Com base nas narrativas dos participantes, observou-se um lugar destacado para o sentimento de não pertencimento ao país de acolhimento, conforme os seguintes exemplos:

"Eu posso dizer que eu tô no Brasil... eu não tô me sentindo em casa sabe... eu só posso dizer que eu tô aqui pra realizá um sonho é isso que eu... pra mim é uma boa experiência estar no Brasil porque nunca sai do meu pais, nunca conheci outra cultura, sempre li nos livros, eu vi poucas coisas... mas ler e viver é outra coisa, [...], minha terra minha vida é Haiti." (P2 - Haiti)

"E claro, em Cabo Verde tu se sente mais a vontade, eu sinto mais a vontade quando tá o lá assim, porque aquela é tua cidade, não tem muitas preocupações, claro, tem teus pais, mas você se sente mais a vontade pra fazer as coisas ali entendeu? Aqui já é diferente, se tu quer fazer uma trilha aqui, ou coisas que eu faria em Cabo Verde, não tem ninguém próximo pra te ajudar. Então essas coisas.” (P3 - Cabo Verde)

"Acho que é bem diferente tipo lá no Haiti tipo tu sento mais em casa né tu tá perto da tua família mas aqui eu... você... eu sinto que eu sou estrangeiro né 
porque tu não sente em casa né. [...] tu fica mais a vontade no teu país do que aqui, é um sentimento assim." (P1 - Haiti)

Tem-se constatado a dificuldade dessa população em se vincular e se projetar no país de acolhimento. No caso dos universitários estrangeiros, isto parece estar relacionado a se perceberem (e serem percebidos também pela sociedade e pela universidade) como em situação temporária, isto é, como se estivessem no país com o único objetivo de terminar os estudos, deixando para um futuro incerto os outros aspectos de suas vidas (Gusmão, 2011). É o que indicam as observações refletidas pela categoria de manifestações sociais, no papel exercido pela sociedade de acolhimento na exclusão dos imigrantes universitários, ao marcar a diferença e sua condição de estrangeiro. O sentimento de não pertencimento à sociedade de acolhida, e mesmo às universidades em que estão inseridos, reforça sua dificuldade de sentir-se parte dela (Fotovatian \& Miller, 2014).

Estritamente relacionado com tais constatações também está a idealização do país de origem - e, consequentemente, sua falta - por parte dos participantes dessa pesquisa, exemplificado da seguinte forma:

“Amigos, família, comida... a vida, a vida em geral sente falta né." (P1 - Haiti)

"É mais ou menos a gente as vezes fica com saudade, meio triste assim, porque a gente ta' afastado de todo mundo, ou seja, de tudo que foi teu mundo até esse momento. Então as vezes é complicado né, mas ah, é uma mistura de vários sentimentos." (P10 - Cuba)

"Se eu pudesse ter tudo aquilo que eu tinha lá. Meus pais é uma coisa que eu queria muito que eles viessem para cá, morar comigo. Assim perto pelo menos. Meus pais, a comida, também. E... É isso. É a comida e a família principalmente." (P14 - Colômbia)

Além do contato com uma nova cultura e com a forma de ser, a imigração também representa um momento de ruptura com os referenciais de origem (Martins-Borges, 2013). Dessa forma, no processo imigratório, existe a presença de uma série de lutos que devem ser elaborados: a família e as relações sociais, a cultura, o país de origem e toda uma série de significantes a ele vinculado. O luto não está relacionado apenas aos elementos dessa cultura de origem, mas também com a sensação de pertencimento e de coerência interna que eram possibilitados pela cultura de origem. É comum a dificuldade na elaboração dos lutos nas etapas inicias da imigração, mas o esperado é que, com o tempo o lugar ocupado por esse objeto nostálgico passe a permitir a integração de elementos do país de acolhimento (Ainslie et al., 2013).

Por fim, outro aspecto de destaque observado na fala de todos os participantes foi o desejo de retornar ao país de origem e lá construir suas vidas:

\section{“Eu volto, se Deus quiser. Terminando eu volto. (P7 - Guiné-Bissau)}

"Pra mim o sentimento pra viver aqui é bom, mas só que o passo seja pra estudar entendeu? Passar o tempo aqui pra estudar é bem adequado, mas fazer a minha vida aqui eu acho que é difícil." (P9 - Haiti)

“Eu queria muito voltar. Voltar para a Colômbia. [...] Mas os planos são de voltar, sabe. Quero muito me estabelecer no país. É esse o meu desejo." (P14 - Colômbia)

Especificamente em relação ao Brasil, não existem dados acerca do número desses estudantes que decide permanecer no país após a conclusão da formação. No entanto, sabe-se que isso ocorre em diversos casos, com objetivo de realizar uma pós-graduação, de conseguir um emprego ou de construir a vida no país (Fonseca, 2009; Silva \& Morais, 2012).

O desejo pelo retorno parece estar relacionado com a idealização do país de origem e com a nostalgia, comum em lutos ainda não elaborados. Nesses casos o sujeito ocupa-se com o passado idealizado e com um futuro no qual o retorno seja possível, superinvestindo essas experiências em detrimento de uma integração com a realidade atual. Mais uma vez é necessário destacar o papel da elaboração do luto para o imigrante, que envolve uma remodelação do mundo interno de modo a integrar referências da nova realidade e cultura externa, na qual o sujeito se encontra (Ainslie et al., 2013).

\section{Considerações finais}

A imigração, mesmo que voluntária, acarreta em uma série de impactos. Dessa forma, o presente artigo teve como objetivo compreender as características do sofrimento psíquico em estudantes universitários estrangeiros. Assim, com base na pesquisa realizada foi possível observar evidências de sofrimento psíquico vinculadas às vivências advindas do contato com a diferença cultural e com as transições e restruturações necessárias ao processo migratório. Por meio da técnica de análise de conteúdo foram observadas três categorias temáticas relacionadas ao sofrimento psíquico dos 
participantes: Sintomas físicos, manifestações sociais e sintomas psicológicos. Percebeu-se uma associação entre essas três dimensões, isto é, todas estão diretamente relacionadas a uma situação conflitiva, que comporta aspectos da identidade e de sua renegociação de forma a manter uma continuidade psíquica entre quem se foi e quem se é. Nesse complexo processo aparece também a dificuldade de elaboração de lutos, que refletem em uma idealização do país de origem e o desejo pelo retorno a ele. Por fim, questiona-se o papel exercido pela sociedade, que constantemente marca a condição de estrangeiro desses sujeitos, reforçando o sentimento de não pertencimento.

Essas questões influenciam diretamente o modo como os imigrantes universitários significam suas experiências migratórias, expressando-as em formas que comprometem sua integração como o isolamento, as dificuldades de adaptação, e o desempenho acadêmico (Gusmão, 2011). Estudos específicos com essa população também têm destacado os impactos na saúde mental dessa população, sendo os principais efeitos: estresse, ansiedade, somatização, isolamento, depressão, confusão identitária bem como sentimento de não pertencimento, de incompetência e de inferioridade (Andrade \& Teixeira, 2009; Khawaja \& Dempsey, 2007; Liu \& Winder, 2014; Yakushko, Davidson \& Sanford-Martens, 2008).

No entanto, ressalta-se que não se pode compreender o sofrimento psíquico dos imigrantes de forma isolada, uma vez que ele é mediado por diversos outros fatores (Martins-Borges, 2013). Assim, deve-se considerar o suporte recebido (tanto anterior à imigração como aquele no país de acolhimento), o tempo de imigração, a rede social, os recursos financeiros, o grau de abertura do país de acolhimento a diferenças culturais e as características psicológicas do sujeito, além das características pessoais de cada sujeito (Andrade \& Teixeira, 2009; Sabóia \& Costa-Fernandez, 2017).

Apesar do presente artigo focar nas dimensões que o sofrimento psíquico ocupa no processo migratório dos estudantes universitários estrangeiros, ressalta-se que uma vez que a migração acarreta momentos de ruptura e ressignificação de sistemas de valores e da própria identidade do sujeito, ela também envolve possibilidades de criação. Particularmente no caso dos estudantes internacionais, destaca-se que é a partir das trocas e interações constituídas pelo contato intercultural prolongado que desenvolvem-se processos de conscientização de suas identidades, de autonomia, de abertura cultural, do aprendizado de uma nova cultura e idioma (Liu \& Winder, 2014; Sabóia \& Costa-Fernandez, 2017).

Dentro desse cenário, é impossível deixar de pensar no papel da universidade na vida dos estudantes universitários estrangeiros. Muito mais do que promover a educação, a universidade permite o contato com outras formas de ser e com outras culturas; além disso, ela cumpre a função, para essa população, de representante da sociedade de acolhida, mediando a relação dos estudantes com a comunidade. Dessa forma, ela é um lugar privilegiado para a realização de estratégias e intervenções de modo a construir formas que permitam a melhor adaptação e integração dos estudantes imigrantes. Nesse sentido, seria essencial o envolvimento das coordenadorias de graduação, pós-graduação e relações internacionais no acompanhamento desses estudantes. Algumas das estratégias recomendadas são os programas de apadrinhamento, que permitam relações com estudantes naturais do país de acolhimento e um suporte inicial anterior à chegada ao país; palestras de orientação a esses estudantes; formação e capacitação de servidores e professores para intervenções que considerem a diferença cultural e os impactos da imigração ao trabalhar com essa população (Andrade \& Teixeira, 2009; Maundeni et al., 2010; McClure, 2007).

Com base nas considerações levantadas por meio desta pesquisa foi possível constatar a dimensão do sofrimento psíquico na vida cotidiana dos estudantes universitários estrangeiros. Desse modo, ressalta-se a importância de espaços em que as dificuldades e os conflitos inerentes ao processo migratório possam ser trabalhados, nomeadamente programas de acompanhamento psicológico (Andrade \& Teixeira, 2009; Yakushko, Davidson, \& Sanford-Martens, 2008). Por fim, tendo em vista o número limitado de estudos nacionais com essa população, ressalta-se a importância de novas pesquisas, no âmbito da psicologia, que investiguem tanto dimensões psicológicas como propostas de intervenções.

\footnotetext{
Referências

Ainslie, R. C., Tummala-Narra, P., Harlem, A., Barbanel, L. \& Ruth, R. (2013). Contemporary Psychoanalytic Views on the Experience of Immigration. Psychoanalytic Psychology, 30, 663-679. https://doi.org/10.1037/a0034588

Andrade, A. M. J. \& Teixeira, M. A. P. (2009). Adaptação à universidade de estudantes internacionais: um estudo com alunos de um programa de convênio. Revista Brasileira de Orientação Profissional, 10(1), 33-44.

Bardin, L. (2002). Análise de Conteúdo. Portugal: Edições 70.
} 
CAPES (2010). Portaria no 092, de 28 de abril de 2010.

Chalungsooth, P. \& Schneller, G. R. (2011). Development of Translation Materials to Assess International Students' Mental Health Concerns. Journal of Multicultural Counseling and Development, 39, 180-191. https://doi. org/10.1002/j.2161-1912.2011.tb00150.x

Constantine, M. G. et al. (2005). Examining the Cultural Adjustment Experiences of African International College Students: A Qualitative Analysis. Journal of Counseling Psychology, 52, 57-66. https://doi.org/10.1037/00220167.52.1.57

Coutinho, M. P. L., Rodrigues, I. F., \& Ramos, R. (2012). Transtornos Mentais Comuns no Contexto Migratório Internacional. Psico, 34(3): 400-407.

Divisão de Temas Educacionais (n.d.). Programas Estudante-Convênio. Recuperado em 15 de outubro de 2016 de http://www.dce.mre.gov.br/PEC/apresentacao.php.

Flick, U. (2014). An introduction to qualitative research. London: SAGE.

Fotovatian, S. \& Miller, J. (2014). Constructing an institutional identity in university tea rooms: the international PhD student experience. Higher Education Research \& Development, 33, 286-297. https://doi.org/10.1080/07294360.20 13.832154

Fonseca, D. J. (2009). A tripla perspectiva: a vinda, a permanência e a volta de estudantes angolanos no Brasil. ProPosições, 20, 23-44. https://doi.org/10.1590/S0103-73072009000100003

Girardi, J. F. (2015). Impactos psicológicos da imigração voluntária: a experiência de universitários imigrantes. Dissertação de Mestrado, Universidade Federal de Santa Catarina, Florianopolis, SC, Brasil. Recuperado de https:// repositorio.ufsc.br/xmlui/handle/123456789/169465.

Gusmão, N. M. (2011). "Na Terra do Outro": a presença de invisibilidade de estudantes africanos no Brasil, hoje. Dimensões, 26(1): 191-204.

Jibrin, M., Boeira-Lodetti, M. \& Martins-Borges, L. (2017). Intervenções interculturais em saúde mental: psicoterapia com imigrantes e refugiados. In: Lussi, C. (Org.). Migrações internacionais: abordagens de direitos humanos. Brasília: CSEM - Centro Scalabriniano de Estudos Migratórios.

Khawaja, N. G. \& Dempsey, J. (2007). Psychological Distress in International University Students: An Australian Study. Australian Journal of Guidance \& Counselling, 17, 13-27. https://doi.org/10.1375/ajgc.17.1.13

Liu, D. W. Y. \& Winder, B. (2014). Exploring foreign undergraduate students' experiences of university. International Journal of Qualitative Studies in Education, 27, 42-64. https://doi.org/10.1080/09518398.2012.736643

Martins-Borges, L. (2013). Migração involuntária como fator de risco à saúde mental. Revista Interdisciplinar de Mobilidade Humana, 21, 151-162. https://doi.org/10.1590/S1980-85852013000100009

Maundeni, T. et al. (2010). Cultural Adjustment of International Students at an African University. Journal of Psychology in Africa, 20, 79-84. Doi: 10.1080/14330237.2010.10820345

McClure, J. W. (2007). International graduates' cross-cultural adjustment: experiences, coping strategies, and suggested programmatic responses. Teaching in Higher Education, 12, 199-217. https://doi.org/10.1080/13562510701191976

OECD. (2012). Education at a Glance: OECD Indicators.

Pirlot, G. (2011). Psychopathologie et psychosomatique psychanalytiques et interculturelles. In Guerraoui, Z. \& Pirlot, G. (Org.). Comprendre et traiter les situations interculturelles: approches psychodynamiques et psychanalytiques (pp. 145-192). Bruxelles: De Boeck. https://doi.org/10.3917/dbu.pirlo.2011.01.0145

Sabóia, D. \& Costa-Fernandez, E. M. (2017). Estratégias identitárias e processos interculturativos na mobilidade estudantil da UFPE/Recife. In Lussi, C. (Org.). Migrações internacionais: abordagens de direitos humanos. Brasília: CSEM - Centro Scalabriniano de Estudos Migratórios. Doi inexistente.

Silva, K. \& Morais, S. S. (2012). Tendência e tensões de sociabilidade de estudantes do Palop em duas universidades brasileiras. Pro-Posições, 1, 163-182. https://doi.org/10.1590/S0103-73072012000100011

Yakushko, O., Davidson, M. M., \& Sanford-Martens, T. C. (2008). Seeking Help in a Foreign Land: International Students' Use Patterns for a U.S. University Counseling Center. Journal of College Counseling, 11, 6-18. https://doi. $\operatorname{org} / 10.1002 / j .2161-1882.2008 . t b 00020 . x$

Nota:

Pesquisa de mestrado realizada na Universidade Federal de Santa Catarina com apoio financeiro da Coordenação de Aperfeiçoamento de Pessoal de Nível Superior - CAPES

Autoras:

Júlia de Freitas Girardi - Doutoranda, Université de Toulouse - Jean Jaurès, Laboratoire Cliniques Pathologique et Interculturelle / LCPI Lucienne Martins Borges - Doutora, Universidade Federal de Santa Catarina.

Endereço para correspondência:

Júlia de Freitas Girardi

Université Toulouse Jean-Jaurès

5 Allées Antonio Machado

31058 - Toulouse, France

<julia.girardii@gmail.com>

Recebido em: 21.12.2016

Aceito em: 17.08.2017 